\title{
Back to the Present: Defending Presentist Time Travel
}

\author{
Paul R. Daniels \\ Monash University
}

BIBLID [0873-626X (2012) 33; pp. 469-484]

\begin{abstract}
Here I defend the compatibility of presentism and time travel against a few objections. Keller and Nelson 2001 argue that, if presentism is at all plausible, presentism and time travel are as compatible as eternalism and time travel. But Miller 2005 and Sider 2005 are not convinced. I reply that for their concerns to have merit, Miller and Sider must assume presentists are committed to positions they need not be; I explain why presentists are not so committed and, in the process, defend Keller and Nelson's position that there is no roadblock to presentist time travel that does not also apply to eternalist time travel.
\end{abstract}

\section{Keywords}

Presentism, Time Travel, Open Future, Causation, Personal Identity.

Presentists are often left out when we talk about time travel. ${ }^{1}$ This might be because time travel talk seems more easily grasped under eternalism. Or it might be because presentism and time travel are thought to be incompatible. Following Keller and Nelson 2001, I find that if presentism is at all plausible, presentism and time travel are as compatible as eternalism and time travel. But I realize some have doubts. Here I address reservations raised by Miller 2005 and by Sider 2005. I argue that both their concerns, while different in nature, can be addressed.

\footnotetext{
${ }^{1}$ Following Sider 2005, I take presentism to be characterized by three traits: past and future objects and events are ontologically unreal, tensed statements are irreducible (as there is nothing to which they can be reduced), and time has an intrinsic direction (which is not reducible to causation). I characterize time travel below.
} 


\section{Features of Time Travel}

First, though, it is worth setting out what a robust conception of time travel requires. Miller (2005: 225) provides a list of criteria for presentist time travel, but it is worth making a more general and robust list of requirements for the kind of consistent backwards time travel stories found in science fiction. So, assume:

(A) time travel into the past is possible,

(B) it is not logically possible to change the past, and

(C) a time traveller causally interacts with the world at her arrival time in the same sort of way as a non-time traveller causally interacts with the world.

And, someone is a time traveller iff:

(D) she travels backwards in time,

(E) there exists a causal relation, $C$, that unites her, as a persisting thing, at multiple times (e.g. the time she departs for, and the time she arrives in, the past), and

(F) there exists a relation, $P$, that is both a necessary and sufficient condition for personal identity across time such that it connects her at her departure time and at her arrival time. ${ }^{2}$

\footnotetext{
${ }^{2}$ Notice that cases where so-called time travellers are mere observers (unseen, unheard, untouchable) at their arrival time are excluded by (C). And (D) rules out stories of just seeing the past or future, delusions of time travel, hibernation, stasis, and the like. (It should also be taken to rule out other experiences similar to time travel, for example travel between parallel universes and people who appear ex nihilo with memories of being from the future but are not appropriately caused to be there.) Note that (E) should be taken as being neutral between perdurantism and endurantism. See Miller (2005: 225) for separate perdurantist and endurantist formulations of this clause. (In my discussion of Sider's objection I use talk of person-stages for ease of discussion, but this should not be taken as a commitment to any particular account of persistence.) (E), coupled with (D), also entails that the relation $C$ must allow backwards causation and, assuming the possibility of instantaneous time travel, causation at a temporal distance. And I take it that this denotes a particular causal ordering such that the arrival of a time traveller in the past is caused by her departure in the future. Further note that, regarding $(\mathrm{F})$, ineligible accounts of personal identity feature temporal continuity. That is, if temporal continuity is part of your favorite account of personal identity, the possibility of time travel will be ruled out for both presentists and eternalists. (Keller and
} 
As for presentism, presentists must at least be able to:

(a) accommodate an account of causation,

(b) accommodate an account of personal identity,

(c) provide an explanation of past- and future-tensed truths, and

(d) provide an explanation of the relations that hold between present and non-present things. ${ }^{3}$

If presentism cannot provide these, its alleged incompatibility with time travel is not a pressing concern.

Like Keller and Nelson, I am not interested in which particular account of causation or personal identity the presentist invokes; nor how she explains past- and future-tensed truths or (things like) crosstime relations. As they say, this has to be done somehow and if 'the presentist cannot answer this challenge, then presentism is hopeless. We are assuming that presentism at least makes it to the starting line' (2001: 337-338). So, insofar as the presentist can do (a) - (d), I believe she can tell a time travel story that features all the same details as an eternalist time travel story. The presentist version of a time travel story will just feature these details as tensed truths properly relativised to the present. ${ }^{4}$ Of course the caveat for this discussion is just that whatever the presentist invokes, it must be compatible with what it takes for someone to be a time traveller. By that I mean, for example, if your favourite account of causation precludes backwards causation, time travel will not be possible - but this caveat also applies to the eternalist.

Nelson, following Lewis 1976, assume a causal continuity account of personal identity, where someone who exists now is the same person as a certain baby that existed in the past, if the right sorts of mental and physical causal chains connect them.)

${ }^{3}$ So even though past and future objects and events do not exist, it is still true that, for example, Shania Twain was born in Canada and that the sun will rise tomorrow. The presentist also needs to say something about why, for example, 'Shania Twain uses electric guitars more than John Denver did' is true even though it concerns relations between a present thing (Shania Twain) and a non-present thing (John Denver) (Keller and Nelson: 337). Here I have in mind the kind of robust presentism defended by John Bigelow 1996.

${ }^{4}$ See Keller and Nelson for an example of such a story. 
With that in mind, consider an intuitively compelling challenge for presentist time travel - the nowhere objection - which may motivate the common view that presentism and time travel are incompatible.

\section{A Naïve Objection}

The nowhere objection (Godfrey-Smith 1980; Grey 1999) argues that, if presentism is true, would-be time travellers have nowhere to go: Since only the present exists, their desired destination does not exist (or, rather, no longer exists). And because no one can go somewhere that does not exist, there is nowhere for a would-be time traveller to go. The eternalist does not share this problem since, if eternalism is true, past, present, and future times all share the same ontological status; an eternalist time traveller's destination always exists.

But Keller and Nelson object: If presentism is plausible, it must be able to account for how non-time travellers 'travel' as ordinary persisting things from one moment to the next. When we began our journey to the next moment it did not yet exist, but it does exist when we arrive: 'One way or another, the presentist has to make room for travel to non-existent times' (2001: 335). So, the presentist is inclined to accept an account of causation, regardless of time travel considerations, where a cause exists (but not its effect) or the effect exists (but not its cause). Since we are discussing time travel,

The presentist must say that all that matters is that given that some cause $C$ occurs in the present, its effect $E$ will occur, (in the case of forwards causation) or did occur (in the case of backwards causation) or that given some effect $E$ occurs in the present, its cause $C$ did occur (in the case of forwards causation) or will occur (in the case of backwards causation). So long as both cause and effect occur when the relevant time is present, that is all that is needed (Miller 2008: 182).

The presentist can therefore treat forward-going time travellers in the same sort of way they treat non-time travellers: even though their arrival time does not (yet) exist when their departure time exists, they will exist when their arrival time does. And, in turn, a similar treatment for backwards-going time travellers: even though their arrival time does not exist (anymore) when their departure time 
exists, they did exist when their arrival time existed. ${ }^{5}$ So the presentist can use the same conception of causality to handle the atypical persistence of time travellers as well (Keller and Nelson 2001: 340$341) .^{6}$

While this naïve version of the nowhere objection is a bad argument, Miller 2005 considers a more menacing inverse version. ${ }^{7}$ Instead of focusing on someone who travels from the present to the past, she considers someone who travels from the future to the present. Assuming presentism and the open future doctrine are both true, for someone to be a time traveller who comes from the future to the present, it must be the case that her departure event will occur - otherwise, how did it come to be the case that she travels back to the present?

According to Miller's open future doctrine, for any time, when it is present, 'it is genuinely indeterminate what events will occur at temporal locations that are in the objective future' (2005: 223). This means the occurrence of a time traveller's departure event is indeterminate at her arrival time as there are possible futures after her arrival event that do not contain her departure event. ${ }^{8}$ Because her departure event may or may not happen, there can be no guarantee that, at her would-be departure time, she will travel into the past. So while it may be plausible to travel from a location that exists to a nonexistent one, it remains impossible to travel from a non-existent

\footnotetext{
${ }^{5}$ Note that this does not commit the presentist to what is known as the secondtime-around fallacy: to say that someone can travel to (her arrival time in) the past is just to say that she is caused to exist at that time when it was the case that it is present; her arrival time does not occur again, and nothing is added to it after her departure time. If it is not the case that she exists at her arrival time when it is present, then it is not the case that she did exist there when it is past and, therefore, not that case that she time travelled there. If she exists at her arrival time when it is present, and bears the right kind of connections to her at her departure time, she is a time traveller.

${ }^{6}$ Sider endorses this reply from Keller and Nelson; Dowe 2000 makes a similar one.

${ }^{7}$ Keller and Nelson (2001: 335, footnote 6) briefly note this inverse nowhere objection as well, but do not recognize it as posing a different challenge.

${ }^{8}$ That is, only events that are not already fixed by the causal order are open and her departure event (as the cause, not effect, of her arrival event) is not fixed by the causal order at her arrival time.
} 
location to one that exists. And since it must be the case that she will depart for the past (otherwise she would just be someone who appeared ex nihilo, not someone who travelled back in time), and a specific future event cannot be guaranteed to happen because the future is open, Miller concludes that the presentist has failed to give a compelling account of time travel; the presentist can only say that at some time, $\mathrm{t}$, a (so-called) time traveller which exists at $\mathrm{t}$ might travel to $t$ (i.e. be caused to exist at $t$ ) from some later time, $t+$.

But I see a few ways the presentist could respond.

REJECT OPEN FUTURE DOCTRINE. Most obviously, the presentist can just reject the open future doctrine. While other Atheories (e.g. the branching time model) may be committed to the open future doctrine, presentism is not. As such, the presentist can simply reply that, if time travel is possible, the open future doctrine is false. A presentist who believes the future is closed can adapt Keller and Nelson's reply to successfully address Miller's inverse nowhere objection since, if there is only one possible way the future could turn out, a time traveller's departure event will happen and cause her arrival event. So, the presentist need not engage with Miller's objection in defence of presentism simpliciter. However, while I think rejecting the open future doctrine is a viable option, and an intuitively obvious response, it might be more than some are willing to concede and it really only sidesteps Miller's concern.

DEFEND COMPATIBILITY WITH OPEN FUTURE DOCTRINE. So let us reconsider Miller's open future doctrine. Here the presentist can reply by conceding that, upon the arrival of an alleged time traveller, it is not yet true that she is a time traveller; only if her departure event does occur, can we, retrospectively, say she was a time traveller. That is, she would not be a time traveller when she arrives, but only in retrospect if the future actualized in the right sort of way. Or, if her departure event does not occur, she would fail to meet the criteria of a time traveller and would just be someone who appeared (possibly ex nihilo) with memories and beliefs as if she were a time traveller. In short, the future must turn out in the right sort of way, from her appearance at her arrival time, for her to be a time traveller.

Since it is possible that she could turn out to be a time traveller, the possibility that she might not cannot serve as a counter-example to the compatibility of presentism and time travel. Taking this option, 
though, does force the presentist to clarify: for someone to be a time traveller she must determinately be a time traveller. This means that, upon her arrival, she is not determinately a time traveller since her departure event may or may not happen; someone is only ever determinately a time traveller once both her departure and arrival event are in the present or past.

To draw an analogy, consider someone with a lottery ticket. On this presentist (strong) open future model, when he buys his ticket it is not true that he owns the winning ticket. But if the future plays out in the right sort of way - if his ticket turns out to be the winning ticket - it will become true that he owns the winning ticket. Here someone can only be a lottery winner in retrospect and, likewise, someone can only be a time traveller in retrospect; both are made true or false by the events that end up happening.

Miller briefly considers a reply along the same lines as this, but dismisses it because the causal work seems 'shadowy at best' and because 'it is hard to make sense of the idea that it can be indeterminate whether $\mathrm{x}$ is the cause of $\mathrm{y}$ or not' (2005: 228). But intuitions can only take us so far in discussions about time travel - after all, a world with time travellers would certainly be a strange world! Granting the possibility that events could be causally indeterminate, or caused ex nihilo, is just the way causation would have to work if presentism, time travel, and the (strong) open future doctrine are true. Strange as it may be, it is certainly conceivable.

ENDORSE (WEAK) OPEN FUTURE DOCTRINE. Alternatively, I also find that the presentist can reply to Miller by disputing her interpretation of the open future doctrine. According to Miller's conception of the open future doctrine, any future event may or may not happen. But a plausible alternative interpretation of what 'the future is open' means is just that, for any time, when that time is present there is at least one future-tensed statement that is indeterminate. Here, then, it is plausible that of all the possible ways the future could be after her arrival time, they each contain her departure event. That is, while it may be indeterminate which specific possible future will be actualized, it is determinate when her arrival event occurs that some appropriate future event will cause her to travel back in time from her departure time. ${ }^{9}$ The presentist who endorses this interpre-

\footnotetext{
${ }^{9}$ Miller (2008: 181-182) describes the open future this way as well, but operates with the understanding that a time traveller's departure event could be absent
} 
tation of the open future doctrine just denies what Miller asserts: 'at $t$, it must be indeterminate whether the time traveller will exist at $\mathrm{t}+$, and whether she will decide to travel back in time.' (2005: 228)

But be sure to note that, by this interpretation, all alternative futures after her arrival event contain all events that make up the personal history of the time traveller: her birth, her departure event, how many people visited the Eiffel tower the day before she departed for the past, and so on. What is indeterminate, according to this view, is what will happen after her departure event (e.g. whether or not there is a sea battle in the Mediterranean the day after she departs for the past). So even though the future is open, an appropriate departure event is guaranteed - it is true when she arrives that she is a time traveller since 'she will depart' is true in all possible futures. ${ }^{10}$ So the (weak) open future doctrine is compatible with 'she will depart' being true at her arrival time. ${ }^{11}$

So the presentist has a myriad of strategies with which to reply to Miller's inverse version of the nowhere objection. Which option is best will depend on the personal priorities of the presentist.

from some future possibilities. So, given that Miller and the (weak) open future presentist can agree that the future is open just if at least one future-tensed proposition is not fixed, the presentist deny that a backwardly causal event (e.g. a time traveller's departure event) can be indeterminate prior to its occurrence, but later than, its effect (e.g. a time traveller's arrival event).

${ }^{10}$ Recognize, though, that this does not mean her arrival event causes future facts like her departure event. The counterfactual dependence must run from future to past: it must be a case of backwards causation for it to be a case of backwards time travel.

${ }^{11}$ Miller (2008: 187-188) also briefly considers a more radical (weak) open future doctrine where both the arrival event (effect) and departure event (cause) occur in all possible futures, even prior to the arrival event - they are determined by the laws of nature and initial conditions of the world. This differs from my reply in an important way: contra Miller, prior to the arrival event, the arrival event may or may not happen; but if the arrival event does happen, then all possible futures contain the departure event. Martinez 2011 develops a parallel argument to my (weak) open future reply, but in defence of branching time. Caveat: Martinez seems to take all possible futures to be real and, those that fail to become actual cease to be real. I am unsure how incompatible possible futures can be equally real, but, regardless, the presentist rejects this: only the present is real and possible futures are ones that may become real. 
In contrast, while Miller's objection explored an incompatibility between time travel and an ancillary metaphysical doctrine the presentist may be incline to adopt, Sider 2005 raised a different, more direct, objection against the possibility of presentist time travel.

\section{Sider and Lewis' Personal/External Time Distinction}

To best explain Sider's worry, consider the following case: A few hundred million years ago a person materialized, seemingly ex nihilo, with the memories and body of someone named Jennifer. She gazed upon the dinosaurs for a few minutes before being eaten by a Tyrannosaurus Rex. In 1991, a baby was born and named Jennifer. This Jennifer grew up with the desire to gaze upon the dinosaurs. In 2011, she found a large box labelled the time machine and cried out 'In a few moments I will view dinosaurs!' She then boldly entered the box and vanished. Say both Jennifers in this story are the same person. Is she a time traveller?

Assuming presentism, I find that if her entry in the box is causally connected in the right sort of way to her appearance in the past, she is a time traveller. But Sider thinks she cannot be. His worry is of the following sort: before she departs, how can the event Jennifer-viewsdinosaurs be something that is going to happen since it is something that already happened millions of years ago?

It might seem like Lewis 1976, with his personal/external time distinction, could address this worry. If employable, this distinction would point out that the concern conflates personal and external time - her viewing dinosaurs is only in the past with respect to external time and only in the future with respect to her personal time:

External time is time itself, global time, the time with respect to which [she is] traveling backwards into the past. Personal time is a measure of the changes undergone by a time traveler. [Her] two-hundred million year journey back in external time counts as taking two minutes of [her] personal time if, during that journey, [she has] undergone two minutes' worth of change - that is, undergone the sorts of changes that normally occur to a person during two minutes of external time (Sider 2005: $330)$.

What this distinction offers is a sense in which it is true that the event Jennifer-views-dinosaurs is located in her future. This is crucial since, 
if it is not something that is about to happen to her, she would be indistinguishable from someone with a temporally disconnected lifespan who once viewed dinosaurs:

That such utterances [e.g. the one made by Jennifer] be correct in some sense is vital to the vindication of time travel, the sort of time travel in science fiction stories anyway. For suppose that [her] dinosaur viewing is in no sense located two minutes in [her] future. Then it seems wrong to say that [she travels] in time. What is true instead is that [she] once viewed a dinosaur, two hundred million years ago. [She] would be no time traveler, only a person with a temporally disconnected lifespan (Sider 2005: 330). ${ }^{12}$

And, contra Keller and Nelson, Sider argues that the presentist cannot employ Lewis's distinction.

Personal time, in the life of a time traveller, is meant to play the same role external time plays in the life of a non-time traveller. But since, according to the presentist, time has an intrinsic direction there is only one sense in which something will actually happen. So if they play the same sort of role, Jennifer's utterance 'In a few moments I will view dinosaurs!' can only mean 'The event Jennifer-viewsdinosaurs is a forthcoming event in the passage of time!' In this case, however, her utterance is false since, once she enters the box, she will cease to exist and will never exist again. It looks like she has no reason to be excited, she should instead be afraid of being annihilated.

But, Sider continues, that is not what she means by her utterance. Jennifer's personal future actually concerns past-tense causal statements while only her external future concerns future-tense statements. If this is the role personal time must play here, the divergence from external time is so significant that personal time fails to play the

${ }^{12}$ What someone with a temporally disconnected lifespan would be like can be difficult to imagine. I take it that Sider means someone, for instance, who appears in the Mesozoic era with certain memories, beliefs, physical structure, and so on who is same person as a certain someone who will, say, be born in 1991 and named Jennifer*. (So, when Mesozoic-Jennifer* utters 'I will be born in 1991' it comes out true.) Sider seems to believe Jennifer* is only someone with a disconnected lifespan even if there exists a backwards causal connection, however I find that Jennifer* is someone with a temporally disconnected lifespan, and not a time traveller, only if there is no backwards causal connection from $20^{\text {th }}$-CenturyJennifer* to Mesozoic-Jennifer* (more on this below). 
same role external time plays in the life of a non-time traveller (since time is not reducible to causation). And,

if personal time bears little similarity to external time then 'personal time' is merely an invented quantity, and is misleadingly named at that. That [Jennifer] will view a dinosaur in [her] personal future amounts merely to the fact that [she] once viewed a dinosaur, and moreover that this is caused by [her] entrance into a time machine (Sider 2005: 333).

So at most the presentist can say something like 'because she enters a time machine, it was the case a few hundred million years ago that she is viewing dinosaurs'. Sider takes this to be, at most, a description of someone with a temporally disconnected life; not someone who travelled back in time. And so, the presentist lacks an appropriate sense of will - one for which it is true that Jennifer, in 2011, will see dinosaurs. ${ }^{13}$

While I agree with the bulk of Sider's analysis, I find he has confused the issue as a matter of statement tense alone, when causation is of the utmost importance. By that I mean Sider casts his light too narrowly and focuses on the wrong part of the presentist metaphysical picture. Granted, presentism simpliciter only concerns itself with the objective sense of what will happen next and, objectively, when Jennifer steps into the box she will cease to exist (and never exist again). Here Sider is right: for the presentist the only real sense in which something will happen is if it is forthcoming in the passage of time. And, insofar as the presentist finds the direction of time to be merely the difference between past- and future-tense operators, Jennifer's utterance, 'In a few moments I will view dinosaurs!' is literally false. But whether someone is a time traveller depends on how her life is causally describable and if person-stages exist at the right times that bear appropriate connections to one another; it depends on whether the person-stage that appears at her arrival time is causally downstream from the person-stage at her departure time.

\footnotetext{
${ }^{13}$ Miller also hints at this same sort of concern, but dismisses it: 'Of course, in some sense the presentist can never travel to the past. Rather, what is the case is that it is now true that some current individual did exist in the past, and that individual's existence in the past is caused by her existence in the present' (2005: 226).
} 
So Sider's objection only works against a presentist whose account of personal identity hinges on tensed facts. For such a presentist Mesozoic-Jennifer can say what will happen to her (e.g. being born in 1991) and have it come out true, but $21^{\text {st }}$-Century-Jennifer cannot say that viewing-dinosaurs will happen to her and have it come out true. Whereas Sider's objection fails against a presentist with a causal account of personal identity, since what will happen to someone here depends on what is causally downstream for her. Here, then, in 2010 gazing upon the dinosaurs is causally downstream for Jennifer. And, as noted earlier, following Keller and Nelson, I assume the presentist can adopt a causal account of personal identity.

To see the importance of the causal connection here, notice that when we talk about what will subjectively happen to someone we are either talking about what is going to happen to her in future temporal locations or what is causally downstream for her. Usually (i.e. when we talk about non-time travellers) these coincide. But they come apart when we talk about time travellers. In the former sense, Jennifer will not view dinosaurs; but in the latter, she will. The presentist can appeal to this causal sense to address worries like the one raised by Sider.

Recall that it was stipulated that the person eaten by a Tyrannosaurus Rex and the person born in 1991 are one and the same. She is either a time traveller or someone with a temporally disconnected life. Sider does not deny the causal connection, but he nevertheless denies it as an instance of travel. Whereas I contend that it only follows that she did not travel if the event of her entering the time machine did not cause it to be the case that she gazed upon dinosaurs.

Consider it this way: Imagine Marty, a would-be eternalist time traveller. Marty is presented with a box labelled the time machine and told that his stepping into it makes it the case that he gazed upon the dinosaurs millions of years ago. Should Marty be afraid that this is actually an annihilation machine? Well, the eternalist can either be afraid or excited about later temporal locations or what is causally downstream. The eternalist does not usually fear nonexistence at later temporal locations for the same sort of reason he does not fear nonexistence at spatially distant locations; fear or excitement is naturally grounded in what is causally downstream for him. So, no, he should not be afraid - but only because his entrance into the box causes his appearance in the Mesozoic Era. That is, as an eternalist he should not be afraid of getting annihilated, even though he does not 
exist at later locations in the space-time block, because what is causally downstream for him is what he cares about (rather than whether he exists causally downstream for others); subjectively, he is about to see dinosaurs because his person-stage at his arrival time in the past is causally later than his person-stage at his departure time. If, instead, Marty's entrance does not cause his appearance in the past, then he should be afraid that the device is actually an annihilation machine, even if he is informed that he exists in the Mesozoic era (since here he would just be someone with a temporally disconnected lifespan).

The presentist has the same sort of options: she can either be fearful or excited about what is forthcoming in the passage of time or about what is causally downstream. For the presentist, fear or excitement may seem more naturally grounded in what is forthcoming in the passage of time, but that need not necessarily be the case. The life of a backwards-going time traveller highlights why it makes sense for the presentist to care about what is causally downstream, even if what is causally downstream is not literally going to happen. Jennifer, our presentist time traveller, should not be afraid of annihilation when she enters the box because, subjectively, dinosaur-viewing is about to happen to her as it is causally downstream for her.

The difference between Marty and Jennifer is just that, after their respective departure events, he exists at locations in the past and she does not, but this is not salient here. It does not need to be the case that there exists a Jennifer gazing upon the dinosaurs after her departure time for her to be a backwards time traveller. (To conceive of backwards time travel in such a way that it requires a time traveller exist at her arrival time after her departure time would, by definition, preclude the compatibility of presentism and time travel.) ${ }^{14}$ What is required instead is that an appropriate person-stage of Jennifer exists when it was the case that her arrival time is present, and that her existence there is causally downstream from the existence of an appropriate person-stage at her departure time (i.e. when her departure time is present).

\footnotetext{
${ }^{14}$ An anonymous referee has queried whether the presentist has the right kind of ontological resources to provide an adequate causal account here, but I assume that the presentist ontology is sufficiently robust in this regard. (Bigelow 1996 is one example of a presentist picture which contains sufficiently rich properties to give us the appropriate kind of relations here.)
} 
Again, for presentism to be plausible, it requires an account of causation that explains how non-time travellers 'travel' to unreal times throughout our normal persistence. While the non-time traveller travels through time ordinarily by being caused at one moment to exist at the next, the time traveller travels through time atypically by being caused at one moment to have been at an earlier one; time travellers persist atypically. The way Sider explains the presentist ability to parse time travel talk is right - Jennifer, literally, is not someone who exists anywhere after her departure time; she, literally, does not go anywhere. But the presentist can distinguish her as a time traveller by leaning on her account of causation. Her status as a time traveller hinges on the causal order of her person-stages, regardless of when they exist. For the presentist, if what is causally downstream for her does not coincide with what is forthcoming in the passage of time, she is a time traveller.

So a presentist metaphysical picture that includes an appropriate account of causation is able to give a sensible answer to the question 'How can the event of someone watching dinosaurs be something that is about to happen and something that already happened millions of years ago?' The answer is just: Her gazing upon the dinosaurs is only about to happen in the sense that it is causally downstream in the order of events that make up her life and is only in the past with regard to the intrinsic direction of time. She is not really about to see dinosaurs, but that is not what is important since the presentist has a relevant sense that we do care about in which Jennifer will view dinosaurs: If the departing Jennifer is the same person as the arriving Jennifer, and the right kind of causal connections hold between her departure event and her arrival event, then her gazing at dinosaurs is something that is subjectively about to happen to her. This is what future-tense statements regarding time travellers must mean.

In the end, Sider misplaces the importance in what we care about when evaluating whether or not someone is a time traveller. All Sider has shown is the incompatibility of presentism with an account of personal identity built around tensed facts and not causal connections. But I take it that presentism is compatible with an appropriate causal account of personal identity.

As a last aside, Sider may just be treading on an ambiguity in 'travel' here: it seems to me that to say Marty and Jennifer travelled to the past is the same as to say Shania Twain travelled from the 1999 to 2000. That is, to say that Shania Twain travelled from 1999 to 
2000 is just to say that a thing called 'Shania Twain' existed at 1999 and then at 2000. Or, put differently, her existence at 2000 is causally downstream from her existence at 1999. This is no different from what is granted when we say Marty and Jennifer travelled from the $21^{\text {st }}$ century to the Mesozoic (i.e. a certain thing existed at both the Mesozoic Era and the $21^{\text {st }}$ century and its existence at the Mesozoic Era is causally downstream from what existed at the $21^{\text {st }}$ century). Even if this turns out to not be something we should properly call travel, it is just as good for our purposes here since it captures what we care about: that Jennifer sees dinosaurs in the Mesozoic Era and has veridical memories of entering a box labelled the time machine.

Of course, these replies to Miller and Sider will not appeal to all presentists. But that was never my aim. The audience of sympathetic presentists might actually be somewhat limited as presentists are under pressure from other challenges to not accept certain positions which are needed in order to coherently believe in time travel. For instance, many may want to deny backward causation, and the resources available to those who reject it are not able to adequately fillin for those who want to believe in the kind of time travel discussed here. ${ }^{15}$ But a characteristic common too many views - including eternalism - is that different pressures push them in different directions; finding the right balance is the overarching challenge. While finding this balance for presentism is beyond the scope of this article, this article does contribute to that end insofar as I have shown why presentism and time travel should not be considered incompatible because of the objections Miller and Sider raised. So my intended audience is appropriately limited: those who dismissed the compatibility of presentist time travel due to the objections raised by Miller and Sider. My purpose here is simply a continuation of Keller and Nelson's: 'to deny what has sometimes been taken to be a defining

\footnotetext{
${ }^{15}$ Moreover, while some presentists might have reservations based on qualms about backwards causation, or causation at a temporal distance, Keller and Nelson argue that such reservations apply equally to eternalism. And because they (and I) want to defend presentist time travel as being as compatible as eternalist time travel, a problem for all is a pressing concern for none. So even though such reservations are serious and while they deserved greater attention, I also ignore them as my aim is specific: reply to the objections raised by Miller and Sider.
} 
difference between (presentism and eternalism): their disagreement over the possibility of time-travel' $(2001: 333){ }^{16}$

Paul R. Daniels

Monash University Department of Philosophy

Melbourne, Australia paul.daniels@monash.edu

\section{References}

Bigelow, John. 1996. Presentism and Properties. Philosophical Perspectives 10 (Metaphysics): $35-52$

Dowe, Phil. 2000. The Case for Time Travel. Philosophy 75(293): 441-451.

Godfrey-Smith, William. 1980. Travelling in Time. Analysis 40(2): 72-73.

Grey, William. 1999. Troubles with Time Travel. Philosophy 74: 55-70.

Keller, Simon \& Michael Nelson. 2001. Presentists Should Believe in Time Travel. Australasian Journal of Philosophy 79: 333-345.

Lewis, David. 1976. The Paradoxes of Time Travel. American Philosophical Quarterly 13: 145-52. Reprinted in Lewis 1986: 67-80.

Lewis, David. 1986. Philosophical Papers, Volume 2. Oxford: Oxford University Press.

Martinez, Manolo. 2011. Travelling in Branching Time. Disputatio 4(26): 59-75.

Miller, Kristie. 2005. Time Travel and the Open Future. Disputatio 1(19): 223-232.

Miller, Kristie. 2008. Backwards Causation, Time, and the Open Future. Metaphysica 9(2): 173-191.

Sider, Theodore. 2005. Traveling in A- and B- Time. The Monist 88: 329-335.

${ }^{16}$ For helpful discussions and comments, thanks to Toby Handfield and John Bigelow. 